Journal of Teacher Education for Sustainability, vol. 19, no. 2, pp. 36-50, 2017

\title{
An Analysis of Transformation of Teaching and Learning of Japanese Schools that Significantly Addressed Education for Sustainable Development
}

\author{
Tomonori Ichinose \\ Miyagi University of Education, Japan
}

\begin{abstract}
Education for Sustainable Development (ESD) requires learner-centred and interactive teaching strategies such as critical thinking, participatory decision-making, value-based learning, and multi-method approaches, all of which to some degree contrast traditional lecture-based teaching practices. As there is very little evidence providing international comparison across different educational backgrounds, the research digs deeper into the effects of a pluralistic ESD approach to teaching in the context of Japanese primary and secondary education. Based on answers from a questionnaire administered by head teachers in 469 ESD schools, the present research shows that teachers recognise that at least in relation to the local environment, community welfare, and depopulation of communities, the students are increasingly aware of their role and the need to act ambitiously to create a sustainable society. In these teacher comments about ESD methods, the main emphases were on the whole system, for example, the use of integrated studies (referred to 37 times), cross-curriculum development (13), and the ESD calendar (12). The fact that ESD is learner-centred (26), learning in the society (23) focused on collaboration with local community, and based on active learning (20) also frequently appeared. The research also reveals that by using local resource materials and conducting experiential activities, students' awareness of their local district deepens, and students then start to tackle with difficulties of local society such as declining population, protection of natural environment, and preservation of traditional culture by themselves. However, it cannot be said that teachers clearly understand their role as coaches and change agents, and there were no reported cases of teachers and students collaboratively designing school activities. Thus, there is still space for more profound teaching and learning growth in ESD in Japan.
\end{abstract}

Keywords: ESD methodology, pluralism, behaviour changes, learner-centred study, integrated study, locality 


\section{Introduction}

The proposal for a Global Action Programme (GAP) on Education for Sustainable Development (2014), a follow-up to the Decade of Education for Sustainable Development (DESD), maintained that Education for Sustainable Development (ESD) should connect key sustainable development issues with teaching and learning, and that it requires innovative participatory teaching and learning methods that empower and motivate learners to take action for sustainable development. This proposal also pointed out that ESD promotes skills such as critical thinking, understanding complex systems, imagining future scenarios, and making decisions in a participatory and collaborative way.

Outlining the basic features of Education for Sustainable Development as a teaching tradition, Stables and William (2002) and Öhman (2005) identified ESD's three essential aspects of holism: connecting the environmental, social, and economic dimensions of Sustainable Development (SD) issues; integrating their past, present, and future implications; and focusing on their local, regional, and global nature. In its core, such an approach aims to nurture wholeness in all aspects of traditionally segmented and compartmentalized educational discourses like those of individual development, relationships between the individual and the world, disciplines of knowledge, educational aims and so on (Pipere, Veisson, and Salite 2015).

After holism, the second essential feature of ESD deals with the processes of teaching and learning. ESD focusses on the development of skills and action competence for sustainability; this pedagogy has been labelled pluralism.

Pluralistic ESD requires learner-centred and interactive teaching strategies, for example, critical thinking, participatory decision-making, value-based learning, and multi-method approaches, all of which to some degree contrast traditional lecture-based teaching practices (e.g., Öhman, 2004; Sandell, Öhman, and Östman, 2005; Corney, 2006; Corney and Reid, 2007; Winter and Firth, 2007, Firth and Winter, 2007; Rudsberg and Öhman, 2010).

Mogensen and Schnack (2010) and Bentham (2013) further emphasise that a key role of ESD in an action competence approach is to develop students' ability, motivation, and desire to play an active role in finding democratic solutions to SD problems and issues. In this light, the purpose of teaching ESD is to empower and motivate students subjectively to take action for sustainable development.

Despite this global commitment and these discussions around ESD-oriented teaching approaches, however, there is very little empirical evidence on how these transformative educational approaches are really applied in the classroom. How effective at empowering and motivating students to take action for sustainable development are the educational approaches of ESD in fact?

This article researches the surveyed schools' efforts concerning the transformation effected by ESD methodology from the viewpoint of head teachers. In addition, as there is very little evidence providing international comparison across different educational backgrounds, the present research digs deeper into the effects of a pluralistic ESD approach to teaching in the context of Japanese primary and secondary education. 


\section{Literature Review Concerning ESD Methodology}

Earlier research on ESD methodology focused on the effects of Environmental Education (EE) and the difference between EE and ESD (e.g., Öhman, 2004; Summers, Corney, and Childs, 2004; Spiropoulou et al. 2007; Walshe, 2008; Pepper and Wildy 2008). Other previous studies focused mainly on geography or science trainee teachers' conceptions (e.g., Summers and Childs, 2007; Summers, Childs, and Corney, 2005; Summers, Corney, and Childs, 2004; Winter and Firth, 2007, Firth and Winter, 2007).

Öhman (2004) found disciplinary differences amongst Swedish upper secondary teachers' ways of conducting EE. Social science teachers taught environmental issues to a higher degree than science teachers, while only $30 \%$ of language teachers taught environmental issues at all. In addition, many teachers did not teach according to an ESD tradition.

Summers, Corney, and Childs (2004) researched student teachers' conceptions of sustainable development in the United Kingdom. Their research showed that many student teachers recognised the centrality of environmental $(87 \%)$, economic $(69 \%)$, and social (49\%) factors in sustainable development.

Summers and Childs (2007) found that starting secondary science teachers recognised the centrality of environmental (72\%), economic (53\%), and social (31\%) factors but just $15 \%$ highlighted all three; when compared with a pre-specified framework, the aspects of sustainable development largely missing had to do with citizenship, preservation of diversity, and uncertainty and precaution in action.

Pepper and Wildy (2008) reported that Western Australian government secondary school teachers focused only on the environmental aspect of sustainability; education for sustainability remained fragmented and vulnerable to changing school conditions. In this study, leadership of education for sustainability occurred only unpredictably and with little vision for the future, with little evidence of alliance-building or collaboration among colleagues.

Borg et al. (2012) referred to the different ways that teachers with different backgrounds recognizedised sustainable development. The greatest uncertainty for teachers is related to the economic dimension of ESD. Science and social science teachers are critical of incorporating economic growth into the concept of sustainable development while language, vocational, and esthetical-practical teachers are not incorporating it at all. Borg, Gericke, Höglund, and Bergman (2014) showed that Swedish teachers were uncertain with respect to their understanding of all three dimensions.

In general, these studies focussed on teachers' overall understanding of ESD environmental, economic, and social - as well as individual teachers' conceptions of ESD, science, geography etc. These studies have mostly focussed on secondary school teacher perspectives and noted the differences in how secondary school teachers from different disciplines and subjects understand sustainable development. As a result, these studies have shown that only a few teachers have a holistic understanding, and that the ecological perspective is the most commonly recognised one.

In contrast, research focussing on students' recognition of ESD is very rare, and shows that ESD influences students' environmental knowledge but does not create a transformation of attitude and behaviour.

Walshe (2008) looked at the impact and understanding of sustainable development among 12- to 13-year-old geography students in the UK, finding that there was a wide range of levels of understanding of the concept of sustainability. Pauw and Petegem 
(2011), based on research from 1287 students 10 to 12 years old from 59 schools (38 eco-schools and 21 control schools), showed that eco-schools influenced their students' environmental knowledge rather than had the environmental affect. The same authors (2013) showed that the effect of environmental values on environmental behaviour is different across different cultural contexts, based on a massive study with a total of 1,833 children 10 to 13 years old from Flanders (Belgium), Guatemala, and Vietnam.

Berglund, Gericke, and Chang (2014) indicate significant differences in the economic dimension of sustainable consciousness between students from Swedish schools that learn using an ESD approach and students from regular schools, but not in the environmental and social dimensions of sustainable consciousness.

Pauw, Gericke, Olsson, and Berglund (2015) collected a large amount of data from 2,413 students from 51 schools across Sweden to study the effectiveness of ESD. Their results indicate that ESD can actually impact student outcomes in terms of sustainable consciousness.

When it comes to teaching methodologies used for environmental education, different teaching traditions have been discussed: fact-based, normative, and pluralistic traditions. The fact-based traditions are based on the belief that if students accept the correct scientific facts, they will automatically take the right actions regarding environmental issues. In the normative tradition, education is recognised as one tool to create an environmentally-friendly society (Sandell, Öhman, and Östman 2005). Pluralistic traditions require learner-centred and interactive teaching strategies, for example, critical thinking, participatory decision-making, value-based learning, and multi-method approaches to transform society, instead of traditional teaching.

Mogensen and Schnack (2010) emphasised that a key role of ESD in an action competence approach is to develop students' ability, motivation, and desire to play an active role in finding democratic solutions to transform society.

Bentham (2013) suggested an ESD approach for developing action competence, involving focus on critical and creative thinking, systemic thinking, and future thinking as ESD skills.

The following research is based on the discussion of the methodology of ESD; the essential feature of ESD deals with the processes of teaching and learning. ESD focusses on the development of skills and action competence for sustainability; this pedagogy has been labelled ESD's pluralism. The schools that the study is looking at use an actionbased, pluralistic approach to teaching ESD.

Thus, with pluralism in mind, this article researches the contributing schools' efforts concerning their implementation of ESD from the viewpoint of school teachers.

\section{ESD in a Japanese Educational Context}

During the Decade of Education for Sustainable Development (2005-2014), which was strongly supported by the Japanese government, the Ministry of Education, Culture, Sports, Science and Technology (MEXT) launched "The Basic Educational Promotional Plan of 2008". This promotional plan positioned the UNESCO Associated Schools as centres for promoting ESD, and gave support to increase the number of the UNESCO Associated Schools in the global school network of UNESCO-leading ESD. This allowed the UNESCO Associated Schools in Japan to take part in the development of the educational content and methods of ESD. After this initiative, the numbers of the UNESCO 
Associated Schools in Japan increased from 24 in January of 2008 to 1,043 in May of 2017. These ESD schools in Japan are primarily public and compulsory schools $(76 \%)$; primary schools make up $52 \%$ of ESD schools.

ESD is extensively present as part of the description of all subjects in the curricula under the Revised National Curriculum Guidelines of 2008. ESD content is most noticeable in geography, civics, natural science, home economics, and physics.

However, as UNESCO (2014) indicated, ESD in Japan is mainly practiced during integrated study time rather than in core subjects. The integrated study time was established when the Curriculum Guidelines, which are the national standards of curricula in Japanese schools, were revised in 1998. These study periods have provided space for teaching and learning approaches that encourage task-based inquiry learning, problemsolving, and participatory learning, which are important components of the pluralistic approaches of ESD.

Table 1

Example of an ESD Calendar (MEXT 2016)

\begin{tabular}{|c|c|c|c|c|c|c|c|c|c|c|c|c|}
\hline \multicolumn{10}{|c|}{ Grade 6 ESD calendar } & \multicolumn{3}{|c|}{ Yanagawa Primary School } \\
\hline Subject & April & May & June & July & August & Sept & Oct & Nov & Dec & Jan & Feb & March \\
\hline \multirow[t]{2}{*}{ Japanese } & \multicolumn{3}{|c|}{ Classroom debate } & \multicolumn{3}{|c|}{$\begin{array}{l}\text { Things that have been } \\
\text { passed down }\end{array}$} & \multicolumn{3}{|c|}{$\begin{array}{c}\text { Re-examining } \\
\text { ourselves }\end{array}$} & \multicolumn{3}{|c|}{$\begin{array}{l}\text { Thinking about world } \\
\text { peace }\end{array}$} \\
\hline & \multicolumn{12}{|c|}{ Creating haiku (short poem) } \\
\hline Math & & & & & & & \multicolumn{6}{|c|}{ Investigating data and averages } \\
\hline Science & \multicolumn{3}{|c|}{$\begin{array}{l}\text { How your body is made } \\
\text { and moves }\end{array}$} & \multicolumn{3}{|c|}{$\begin{array}{l}\text { Living things and their } \\
\text { environment }\end{array}$} & \multicolumn{3}{|c|}{$\begin{array}{l}\text { How the earth is made } \\
\text { and changes }\end{array}$} & \multicolumn{3}{|c|}{$\begin{array}{l}\text { Living things and the } \\
\text { global environment }\end{array}$} \\
\hline Social studies & \multicolumn{3}{|c|}{$\begin{array}{l}\text { The people who made } \\
\text { 'Edo(Tokyo)' culture }\end{array}$} & \multicolumn{3}{|c|}{$\begin{array}{l}\text { People living under } \\
\text { long-term state of war }\end{array}$} & \multicolumn{3}{|c|}{$\begin{array}{c}\text { Countries with strong } \\
\text { ties to Japan }\end{array}$} & \multicolumn{3}{|c|}{$\begin{array}{l}\text { The future of the world and } \\
\text { Japan's role }\end{array}$} \\
\hline Integrated & \multicolumn{4}{|c|}{ Launching out into the future } & \multicolumn{4}{|c|}{$\begin{array}{l}\text { Investigating local history, talking } \\
\text { about your city }\end{array}$} & \multicolumn{4}{|c|}{$\begin{array}{l}\text { What is world peace? What can we } \\
\text { do to achieve it? }\end{array}$} \\
\hline English & \multicolumn{12}{|c|}{ Can you introduce your home town? } \\
\hline Special activities & \multicolumn{9}{|c|}{ Making sushi rolls } & \multicolumn{3}{|c|}{$\begin{array}{c}\text { Hosting Yanagawa Local } \\
\text { Festival }\end{array}$} \\
\hline Moral education & \multicolumn{3}{|c|}{ Cheers for longevity } & \multicolumn{3}{|c|}{$\begin{array}{l}\text { The good old days } \\
\text { Learn about past }\end{array}$} & \multicolumn{3}{|c|}{ We are the children } & \multicolumn{3}{|c|}{$\begin{array}{l}\text { If the world were a village } \\
\text { of } 100 \text { people }\end{array}$} \\
\hline \multicolumn{13}{|l|}{ Music } \\
\hline Art & \multicolumn{12}{|c|}{ Express myself of 12 years' old } \\
\hline Sport & \multicolumn{6}{|c|}{ Pathogens and the body's resistance } & \multicolumn{6}{|c|}{ Anti-drug abuse, tobacco, alcohol, medicine } \\
\hline Home economics & \multicolumn{9}{|c|}{ Learn about everyday food and the basics of cooking } & & \multicolumn{2}{|c|}{$\begin{array}{l}\text { Your Growing } \\
\text { up }\end{array}$} \\
\hline $\begin{array}{c}\text { Environmental } \\
\text { education }\end{array}$ & \multicolumn{5}{|c|}{$\begin{array}{l}\text { International understanding, Culture and } \\
\text { cooperation }\end{array}$} & \multicolumn{5}{|c|}{ Human rights/life education } & Learn & ng skills \\
\hline
\end{tabular}

The ESD calendar, which was developed by Toshio TESHIMA, principal of a primary school in Tokyo, shows how all subjects, integrated study time, extra-curricular 
activities, and so on are linked by content in each grade over the course of the year; color-coded units are connected with a line to clearly show their associations (see Table 1).

The aim of the present research is to dig deeper into the effects of a holistic ESD approach to content and a pluralistic ESD approach to teaching in the context of Japanese formal education. Although ESD has been part of the curriculum in Japan for several years, very little research has been conducted to ascertain its effectiveness at empowering and motivating students to take action for sustainable development; thus, research on the Japanese interpretation of ESD is needed; its integration into schools has certainly been different than in Europe (e.g., in Sweden and the UK, cited above), which is mainly focused on secondary education and individual teachers of different subjects.

\section{Research Question and Methods}

As mentioned above, previous studies have mostly focussed on secondary school teacher perspectives and noted the differences in how secondary school teachers from different disciplines and subjects understand sustainable development. In Japan, ESD curriculum has been constructed by linking with other subjects and areas (such as moral education and extracurricular activities), and it is integrated through the whole school curriculum.

This study intends to look at ESD in Japan (a rarely studied topic) from the viewpoint of primary and secondary school teachers (also a rarely studied topic). Thus, the main research question is the creation of a pluralistic ESD approach to teaching in the context of Japanese formal education. To answer this question, the issue will be considered from the viewpoint of schoolteachers in Japan.

This study employs document analysis of the questionnaire survey, which is form of qualitative research. In the document analysis, documents are interpreted and reviewed multiple times and remain unchanged by the research process. In addition, KH Coder (open-source software for quantitative content analysis and text data mining developed by Higuchi Kouichi) was used for metric text analysis of this text data. Using the software, it was possible to measure the frequency of words and then derive basic concepts from the data. In addition, a co-occurrence network was configured. This is used to reconstruct underlying perspectives by extracting frequently used lexical items and their combinations.

The Japanese Ministry of Education, Culture, Sports, Science and Technology (MEXT), together with the Asia-Pacific Cultural Centre for UNESCO (ACCU), conducts an annual questionnaire in all Japanese UNESCO Associated Project Network (ASPnet) schools. These questionnaires ask about multiple aspects of the UNESCO Associated Project, including the effectiveness and challenges of ESD. The general overview is released on the MEXT website (MEXT, 2016).

The present research, using the responses to MEXT survey question no. 19 for the year 2016, analyses the change created by the UNESCO Associated School project and the effectiveness of teaching and learning under ESD in the UNESCO Associated Schools. Question no. 19 is as follows: "Explain the effectiveness of the transformation of teaching and learning, after your school began participating as the UNESCO Associated School project and became a school which addressed ESD".

In 2016, a total of 469 schools, including 228 primary schools, 92 lower secondary schools, 4 primary lower secondary schools, 34 secondary schools, and 84 upper secondary schools responded to the questionnaire survey. 


\section{Research Analysis and Findings}

\subsection{Transformation of Teaching}

Question no. 19 asked about the effectiveness of the transformation of teaching and learning after participating in the UNESCO Associated School project and becoming a school that addresses ESD. The questionnaires were administered to the head teachers, who are the ones responsible for ESD practices; comments were collected from 253 schools. Figure 1 shows a co-occurrence network reconstruction of the underlying concepts, created by extracting frequent (appearing more than 16 times) vocabulary items. The following comments are typical ones derived from synthesis of all teachers' comments.

Open-ended comments were collected from the teachers. In the following data, 'P' stands for primary school teachers, 'LS' stands for lower secondary school teachers, and 'US' means upper secondary school teachers.

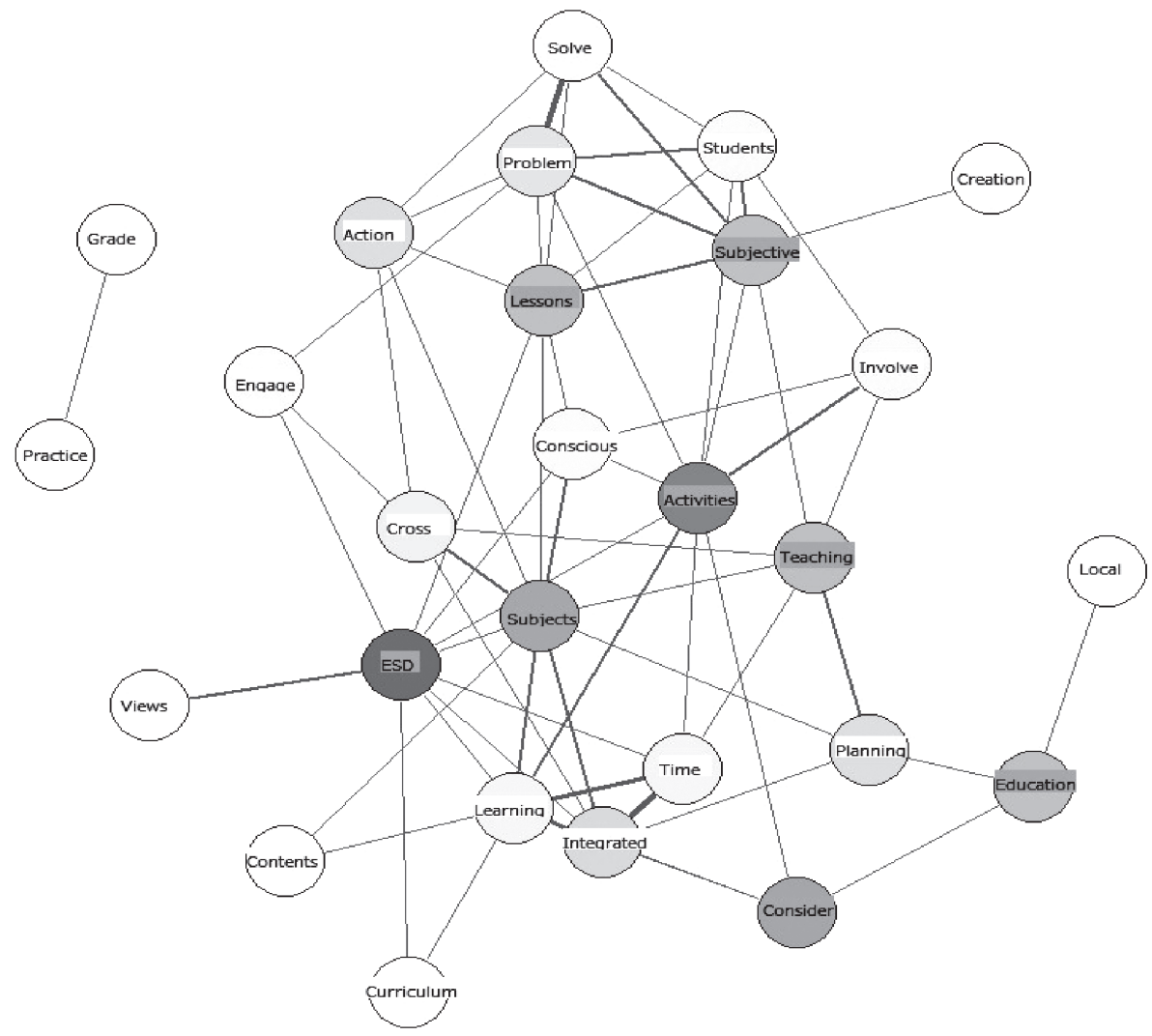

Figure 1. Co-occurrence network for ESD methodology

\subsubsection{ESD Calendar and Cross-curriculum}

Many teachers referred to the ESD calendar, which makes an integrated study a regular subject, and various dates of school events on the schedule for the year. The ESD calendar also assists in the clarification and materialisation of the learning content.

Here are some of the teachers' comments regarding the ESD calendar: 
"Making the ESD calendar led teachers to think systematically about the relationship between integrated study time, life science, etc." (P)

"We made the ESD calendar and began to think about the connections between integrated study time and learning and other academic subjects." (P)

"Our schoolteachers advanced the research of study materials from the viewpoint of ESD, so clarification and materialisation of the learning content was advanced, since the content of instruction was carefully selected." (P)

"We added various dates of school events, integrated study activities, life science, and classroom activities into the ESD calendar so that we can work systematically with vision." (P)

Some teachers referred to the cross-curriculum, which is the same approach as the ESD calendar.

“Cross-curriculum was created. We conducted lessons which involved students' direct experiences." (P)

"Mainly focusing on integrated study time activities, we discussed how to combine all curricula in a cross-sectional and integrated manner." (P)

"We plan lessons utilising academic knowledge and skills cultivated by each ordinary subject into integrated studies." (P)

\subsubsection{Learner-centred Learning}

Achieving a shift to learner-centred, subjective learning is usually mentioned as a key factor in the effectiveness of ESD. Active learning plays an important role in this context. The Japanese Ministry of Education has recently promoted 'active learning' as part of educational reform.

“Transformation from teaching by injecting knowledge to subjective learning by the students was advanced, using active learning, facilitators, workshops etc." (P)

"Previously, tasks and activities were given from the teacher's point of view. Now, school education has shifted; for example, students find out issues subjectively and collaboratively, and they work to find solutions to the problems cooperatively." (P)

"With a focus on active learning, we are conscious of the process of discussion." (LS)

\subsubsection{Collaborative Lessons}

Previous studies mostly focused on secondary school teachers' conceptual understanding of ESD; a majority of those teachers recognised the centrality of environmental perspectives. However, a problem with recognising that environmental issues are central will be cleared up if various individual teachers collaborate to manage sustainable lessons. Teachers stressed that collaborative lessons created by teachers of different subjects moved forward because of the enhancement of ESD.

"Before, only single professional teachers were responsible for their teaching. Now, experimental and advanced teaching (of ESD) has been developed, such as collaborating with various institutions and using human resources." (US)

"The number of teachers who manage lessons using active learning methods, collaborative classes between science and English, English teachers teaching subjects other than English: these types of pedagogy have been promoted as "scholarship support projects" by the Board of Education. Now teachers are discussing the development of collaborative lessons." (US) 
"We are able to arrange lessons not just to transfer knowledge to the students but also to adopt a participatory learning approach that emphasises exploration and practice with experience." (US)

\subsubsection{Locality}

Something unique to teaching and learning in the Japanese school system is the concept of 'locality' or 'district', which frequently appeared in the responses. Familiarising students with local issues allows them to tackle the problems of local districts and to sustain those districts' advantages: the beauty of nature, local products, history and culture, etc.; this is a central learning style in ESD. As a result, students gain love for their local area and local pride is promoted.

"Through activities used to familiarise students with the river, investigate the river, and protect the river of our district, ESD teaches how to work on various activities to support students' love and pride for their local district." (P)

"During integrated studies, a teaching method was developed; students were able to think how to sustain their excellent point[s] of their district in the future, and act and disseminate information on their own." (P)

"The combination of teaching material from local educational resources and studentcentred learning increased." $(\mathrm{P})$

The following comment was typical in the way that it expressed the transformation of teaching in ESD, commenting on active learning and collaboration among different subjects, schools, and local communities.

"Language activities and active learning are actively adopted in classes. Students' ability to think, expressive skills, and problem-solving skills have been increased in each subject. In addition, the sense of collaboration among different subjects, schools, and local communities takes place in the school, and the utilisation of local educational resources is promoted'. (P)

\subsubsection{Critical Thinking and Democratic Decision-Making}

As noted, pluralistic ESD requires learner-centred and interactive teaching strategies such as critical thinking, participatory decision-making, value-based learning, and multimethod approaches, instead of traditional teaching.

In these teacher comments about ESD methods, the main emphases were on the whole system, for example, the use of integrated studies (mentioned 37 times), crosscurriculum development (13), and the ESD calendar (12). The fact that ESD is learnercentred (26) learning in the society (23) focussed on collaboration with local community and based on active learning (20) also frequently appeared. In contrast, critical thinking and democratic decision-making, both found in the study by Mogensen and Schnack (2010), were never referred to in the Japanese context of ESD.

\subsection{Transformation of Learning}

The above-mentioned results reflect the change in the teaching methodology adopted or undergone by teachers teaching ESD. There were also a few comments about the 'transformation of students' learning'.

To understand this latter transformation, the present research analyses question no. 16 from the 2016 questionnaire results: "Comment on the effectiveness of the trans- 
formation of students after participating in the UNESCO Associated School project and becoming a school that addresses ESD". All in all, 265 comments on this question were collected.

\subsubsection{Behaviour Changes}

In these comments, taken as a whole, teachers indicated that students began to be aware of sustainable issues and view them as their own problems. Teachers also emphasised that the awareness led to behaviour changes.

"Students began to be aware of energy and environmental problems as their own problems. That is because students started to learn about the connection between their daily life and energy, the natural environment." (P)

"Students increase their motivation to think and practice what they can do by themselves." (P)

“Students' ability to solve problems, ability to communicate, ability to take action to create a sustainable society have been increasing." (P)

"The number of children who consider and work for the improvement of their local district has increased.” (P)

\subsubsection{Local ESD Study}

Similar to what we saw with question no. 19, 'local' and 'district' frequently appeared.

"By developing activities which were linked with local communities and related organisations, we were able to have a variety of genuine experiences." (P)

"The number of students who have learned to act ambitiously to protect the local environment has increased, along with the mind-set of loving their local regions." $(\mathrm{P})$

"Through lessons related to the environment, depopulation of communities, disabilities (handicaps, braille, sign language experience), students are increasingly aware of their roles in a sustainable society." (LS)

These comments help reveal the typical student learning style in ESD in Japanese compulsory education. By using local resource materials and conducting experiential activities, students' awareness of their local district deepens, and students then start to tackle with difficulties of the local society such as declining population, protection of natural environment, and preservation of traditional culture by themselves. These actions generally positively affect student motivation toward learning, and lead to the cultivation of students' love and pride towards their local community (see Fig. 2).

Bentham (2013) suggested that the ESD teaching and learning approach should include development of action competence; involve decision making and communitybased decision making (for instance, debates and action plans); engage in community and social development activities, active learning methods (for instance, environmental impact assessments); explore ways of solving local contextually relevant problems. The context of teaching and learning in Japanese ESD schools is in the line of this concept.

"By using local resource materials and conducting experiential activities, students' awareness of their local district has deepened. Students also pick up on local issues and problems depending on their own awareness, and tackle these issues subjectively." (P)

“Students' communication skills improved because of communication with local people. Students' civic pride (pride in the local community) increased because they learned about their local district. Motivation to learn increased throughout the use of these activities." (US) 


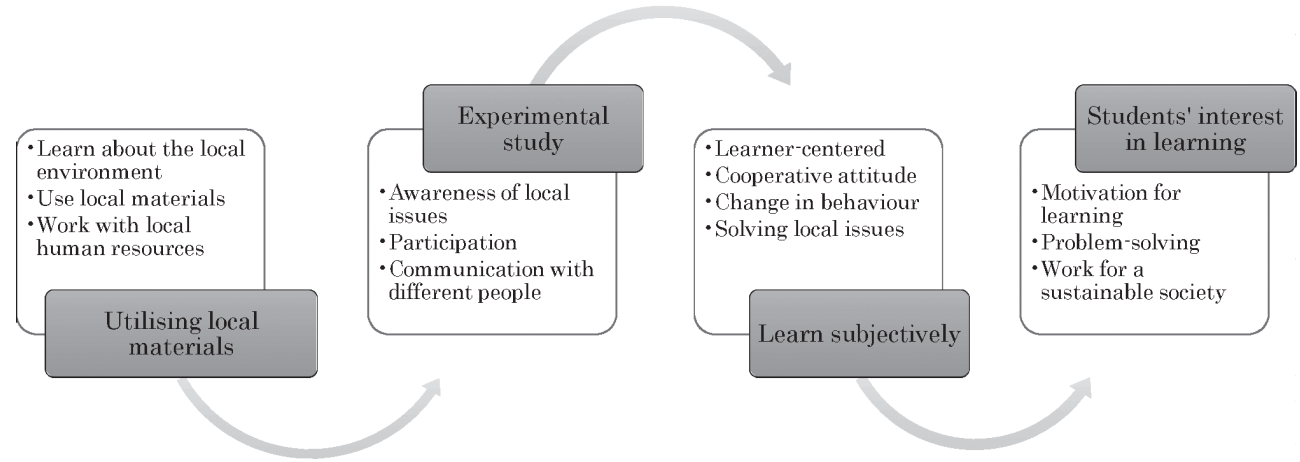

Figure 2. Learning styles in the local ESD study in Japanese compulsory education

The holistic understanding of ESD has three essential aspects, each itself tripartite: connecting the environmental, social, and economic dimensions of Sustainable Development $(\mathrm{SD})$ issues; integrating their past, present, and future implications; and focusing on their local, regional, and global nature. Based on the analysis of the comments regarding student transformation, environment and nature came up most often (appearing 87 times), followed by society and culture (64 times); economy appeared only once. However, the most emphasised concept was 'local (community)', which appeared 183 times.

This means that in the context of education in Japan, local community, including issues such as disruption of local society and economy because of declining population, is the topic whose relevance is most keenly felt. This reflects the fact that most of the Japanese ESD schools are primary, and so many of the study topics and materials that they select are from their school district and local area, which is the most meaningful geographical frame for young children.

\subsection{International Comparison}

Laurie, Tarumi, McKeown, and Hopkins (2016) carried out studies in 18 countries to identify contribution of ESD to high-quality education. One main question posed by their research was, "How can ESD promote innovation in the teaching-learning conceptual framework?”

The results of research conducted by Laurie et al. demonstrated that ESD contributed to improved teaching, yielded a strong argument for maintaining and even augmenting its role in education systems, and emphasised that ESD prompted innovative teaching approaches and methodologies such as project-based learning, experiential education, cooperative and peer learning, as well as teaching and feedback. As mentioned above, similar transformations are very clear in the present research.

The same authors also noted that the focus in many ESD schools is changing from teaching to learning, as teachers come to understand their role more as that of coaches and change agents and are no longer constrained to traditional roles (the study was conducted in Australia, Belgium, and Latvia). Furthermore, cases of teachers and students designing school activities collaboratively were also reported (the study was conducted in Finland).

The present research also revealed that school education had shifted, with more student activity related to finding out about issues subjectively and collaboratively, and 
working collaboratively to find solutions to problems. Learner-centred classrooms have also been realised effectively in the ESD content in Japan.

However, from the present research, it cannot be said that teachers clearly understand their role as coaches and change agents, and there were no reported cases of teachers and students collaboratively designing school activities. Therefore, there is still space for more profound teaching and learning growth in ESD in Japan.

\section{Conclusion}

A key role of ESD in an action competence context is to develop students' ability, motivation, and desire to play an active role in finding democratic ways of transforming society for sustainability. Although there are many arguments about the effectiveness of ESD, the comments about the Japanese public education system by the teachers surveyed here indicate that at least in relation to the local environment, community welfare, and depopulation of communities, the students are increasingly aware of their role and the need to act ambitiously to create a sustainable society. It appears that the methods of ESD are effective at empowering and motivating students to take action for sustainable development in the context of Japanese primary and secondary education.

In the present research, the most frequently appearing concept in relation to both questions is 'local (community)'. A typical student learning style was familiarising themselves with local issues to tackle the problems of local districts, and thinking about how to sustain local advantages by engaging local skills. As a result, students are expected to gain love for and pride in their local district.

Concerning the pluralistic nature of ESD, in Japan, the ESD curriculum is integrated throughout the whole school and linked with the integrated study time and other subjects and areas. The whole school system (e.g., integrated studies, cross-curricular activities, and the ESD calendar) is the typical approach for Japanese teachers. Integrated study activities, ordinary subjects, and classroom activities are all connected on the ESD calendar, so that schoolwork systematically combines with a vision toward sustainability.

On the other hand, critical thinking and democratic decision-making, which were important in previous studies (Mogensen and Schnack 2010; Bentham 2013), were never referred to in the Japanese ESD context. In addition, teachers did not seem to understand their role as coaches and change agents, and there were no cases of teachers and students collaboratively designing school activities. There is thus still space for more profoundly learner-centred classrooms in Japanese education.

In an international comparative study, Laurie et al. (2016) stated that ESD was best implemented when issues were addressed in multidisciplinary ways and across curricula. When collaborating on interdisciplinary projects, multidisciplinary approaches enable teachers to learn about curriculum content in areas outside of their specialty. The present research supported this idea, as teachers emphasised that collaborative lessons with teachers from different subjects were effective for the enhancement of ESD. As one teacher noted, "Before, only a single professional teacher was responsible for their [own] teaching. Now, advanced teaching of ESD has been developed using collaboration with various organisations and human resources".

Previous studies on individual teachers' experience of ESD mostly focused on secondary school teachers; these studies showed that only a few teachers had a holistic understanding of ESD. However, these issues can be mitigated if teachers are collaborating 
on interdisciplinary projects. Therefore, further research should focus on these types of approaches and on determining the effectiveness of the whole-school approach to ESD.

Acknowledgements

The present research has been supported by JSPS Grant-in-Aid for Scientific Research (C), Grant Number J150100020. We would like to thank Editage (www.editage.jp) for English language editing.

\section{References}

Bentham, H. (2013). Clearing the Path that Has Been Laid: A Conceptualisation of Education for Sustainable Development. Journal of Teacher Education for Sustainability, 15(2), 25-41.

Berglund, T., Gericke, N., \& Chang-Rundgren, S.-N. (2014). The Implementation of Education for Sustainable Development in Sweden: Investigating the Sustainability Consciousness Among Upper Secondary Students. Journal Research in Science \& Technological Education, 32, 318-339.

Boeve-de Pauw, J., \& van Petegem, P. (2011). The Effect of Flemish Eco-schools on Student Environmental Knowledge, Attitudes and Affect. International Journal of Science Education, 33, 1513-1538.

Boeve-de Pauw, J., \& van Petegem, P. (2013). The Effect of Eco-schools on Children's Environmental Values and Behaviour. Journal of Biological Education, 47, 96-103.

Boeve-de Pauw, J., Gericke, N., Olsson, D., \& Berglund, T. (2015). The Effectiveness of Education for Sustainable Development. Sustainability, 7(11), 15693-15717.

Borg, C., Gericke, N., Höglund, H., \& Bergman, E. (2012). The Barriers Encountered by Teachers Implementing Education for Sustainable Development: Discipline Bound Differences and Teaching Traditions. Research in Science \& Technological Education, 30(2), 185-207.

Borg, C., Gericke, N., Höglund, H., \& Bergman, E. (2014) Subject- and Experiencebound Differences in Teachers' Conceptual Understanding of Sustainable Development. Environmental Education Research, 20(4), 526-551.

Corney, G. (2006). Education for Sustainable Development: An Empirical Study of the Tensions and Challenges Faced by Geography Student Teachers. International Research in Geographical and Environmental Education, 15(3), 224-240.

Corney, G., \& Reid, A. (2007). Student Teachers' Learning about Subject Matter and Pedagogy in Education for Sustainable Development. Environmental Education Research, 13(1), 33-54.

Firth, R., \& Winter, C. (2007). Constructing Education for Sustainable Development: The Secondary School Geography Curriculum and Initial Teacher Training. Environmental Education Research, 13(5), 599-619.

Laurie R., Tarumi, Y., McKeown R., \& Hopkins, C. (2016) Contributions of Education for Sustainable Development (ESD) to Quality Education. Journal of Education for Sustainable Development, 10(2), 1-17.

McKeown, R., \& Hopkins, C. (2003). EE/ESD: Defusing the Worry. Environmental Education Research, 9(1), 117-128. 
Ministry of Education, Culture, Sports, Science and Technology, Japan National Commission for UNESCO Office of the Director-General for International Affairs. (2016). A Guide to Promoting ESD (Education for Sustainable Development (first edition), 23-24, Tokyo, Japan.

Ministry of Education, Culture, Sports, Science and Technology, Japan National Commission for UNESCO Office of the Director-General for International Affairs. (2016). Unesco-Associated School Questionnaire Survey in 2016, Tokyo, Japan. Available at http://www.mext.go.jp/unesco/004/1339976.htm (Accessed 8 August 2017).

Mogensen, F., \& Schnack, K. (2010). The Action Competence Approach and the 'New' Discourses of Education for Sustainable Development, Competence and Quality Criteria. Environmental Education Research, 16, 59-74.

Öhman, J. (2004). Moral perspectives in selective traditions of environmental education: conditions for environmental moral meaning-making and students' constitution as democratic citizens. In Learning to Change Our World? Swedish Research on Education \& Sustainable Development, Per Wickenberg et al. (eds.), 33-57. Lund: Studentlitteratur.

Öhman, J. (2008). Values and democracy in education for sustainable development. Liber: Malmö, Sweden.

Pepper, C., \& Wildy, H. (2008). Leading for Sustainability: Is Surface Understanding Enough? Journal of Educational Administration, 46(5), 613-629.

Pipere, A., Veisson, M., \& Salīte, I. (2015). Developing Research in Teacher Education for Sustainability: UN DESD via the Journal of Teacher Education for Sustainability. Journal of Teacher Education for Sustainability, 17(2), 5-43.

Rudsberg, K., \& Öhman, J. (2010). Pluralism in Practice: Experiences from Swedish Evaluation, School Development and Research. Environmental Education Research, 16, 95-111Sandell, K., Öhman, J., \& Östman, L. (2005). Education for sustainable development. Studentlitteratur: Lund, Sweden.

Scott, W., \& Gough, S. (2003). Sustainable Development and Learning: Framing the Issues. London: Routledge/Falmer.

Spiropoulou, D., Antonakaki, T., Kontaxaki, S., \& Bouras, S. (2007). Primary Teachers' Literacy and Attitudes on Education for Sustainable Development. Journal of Science Education and Technology, 16, 443-450.

Stables, A., \& William, S. (2002). The Quest for Holism in Education for Sustainable Development. Environmental Education Research, 8(1), 53-60.

Summers, M., Corney, G., \& Childs, A. (2004). Student Teachers' Conceptions of Sustainable Development: The Starting-Points of Geographers and Scientists. Educational Research, 46(2), 163-182.

Summers, M., Childs, A., \& Corney, G. (2005). Education for Sustainable Development in Initial Teacher Training: Issues for Interdisciplinary Collaboration. Environmental Education Research, 11(5), 623-647.

Summers, M., \& Childs, A. (2007). Student Science Teachers' Conceptions of Sustainable Development: An Empirical Study of Three Postgraduate Training Cohorts. Research in Science \& Technological Education, 25(3), 307-327.

Trudi, V., \& Marie, C. (2003). The Effects of an Environmental Education Program on Students, Parents, and Community. Journal of Environmental Education, 34, $12-15$. 
UNESCO. (2005). UN Decade of Education for Sustainable Development 2005-2014 [international implementation scheme]. Paris: UNESCO.

UNESCO. (2014). Shaping the Future We Want. UN Decade of Education for Sustainable Development (2005-2014) Final Report. Paris, France.

Walshe, N. (2008). Understanding Students' Conceptions of Sustainability. Environmental Education Research, 14(5), 537-528.

Winter, C., \& Firth, R. (2007). Knowledge about Education for Sustainable Development: Four Case Studies of Student Teachers in English Secondary Schools, Journal of Education for Teaching, 33(3), 341-358.

Correspondence concerning this paper should be addressed to Tomonori Ichinose, Prof., Research Institution for Capacity Development of Education (RICDE), Miyagi University of Education, 149 Aobaku Aramaki Azaaoba, Sendai, Miyagi, Japan, Postcode 9800845. Email: ichinose@staff.miyakyo-u.ac.jp 